\title{
A Lei 10.639 e o Ensino de Geografia: Construindo uma agenda de pesquisa-ação
}

\author{
Renato Emerson dos Santos \\ Prof. Adjunto da FFP/UERJ
}

\section{Resumo}

O artigo apresenta a estrutura de um programa de pesquisa sobre a Lei 10.639 e o ensino de Geografia. Considerando o Movimento Negro como ator central na construção da Lei, busca-se retomar a complexidade de sentidos da pauta construída nos processos de disputa pela Educação enquanto instrumento da luta anti-racismo. Tal complexidade se desdobra num conjunto de cinco vertentes de investigação: (i) Inserção e Revisão de conteúdos programáticos do currículo Praticado de Geografia; (ii) Revisão de Práticas, Materiais e Métodos Pedagógicos; (iii) Gestão das Relações Raciais no Cotidiano Escolar; (iv) Relações de Poder na Construção do Currículo Praticado na Escola; (v) Movimento negro, lutas na Educação e escalas da política.

Palavras-Chave: Relações Raciais e Educação; Ensino de Geografia; Lei 10.639; Pesquisa em ensino de Geografia.

\begin{abstract}
This article presents the structure of a research program about the 10,639 Law and Geography teaching. Taking the Brazilian Black Movement as key actor to the Law, it shall bring the complexity of meanings from the movement's agenda, in which Education appears as instrument or anti-racism struggle. So, five lines of investigation are created: (i) Insertion and revision of program contents on practiced curriculum of Geography; (ii) Revision of practices, materials and pedagogical methods; (iii) Management of race relations on school's everyday life; (iv) Power relations on school's practiced curricula building; (v) Black Movement, educative struggles and politics of scale.
\end{abstract}

\section{Introdução}

Este texto tem o objetivo de expor a construção dos marcos lógicos de um programa de investigação sobre a Lei 10.639 e o ensino de Geografia. Tal construção é na verdade, a atribuição de complexidade ao objeto, que no caso enseja a relação entre interpretações sobre o que é (e, o que deve ser) a 
aplicação da Lei 10.639 e interpretações sobre o que é (e o que deve ser) o ensino de Geografia. Não é muito comum publicar (no sentido de tornar público, compartilhar) a construção de programas de investigação, mas sim, seus resultados. Acreditamos, entretanto, que as interpretações sobre a Lei e sobre (ensino de) Geografia estruturantes da investigação são tão frutíferas quanto os resultados - ou, até mais do que eles, na medida que inspiram temas de pesquisa.

A Lei 10.639, promulgada em janeiro de 2003, é atualmente o principal instrumento de combate ao racismo no campo da educação. Fruto de lutas históricas do Movimento Negro Brasileiro, ela vem tendo sua aplicação marcada por uma pluralidade de formas de atuação deste movimento social, que dá cada vez maior amplidão e complexidade aos desdobramentos da Lei.

A Lei reposiciona o negro e as relações raciais na educação - transformando em denúncia e problematização o que é silenciado (como, p. ex., o racismo no cotidiano escolar), chamando a atenção para como conhecimentos aparentemente "neutros" contribuem para a reprodução de estereótipos e estigmas raciais e para o racismo. A 10.639 nos coloca o desafio de construir uma educação para a igualdade racial, uma formação humana que promova valores não racistas.

Defendemos aqui a idéia de que o ensino de Geografia pode ser instrumento de uma educação para a igualdade racial. O que apresentamos são os marcos lógicos e algumas idéias de um processo de investigação que temos desenvolvido desde 2008. Tal processo tem, em sua centralidade, 0 acompanhamento e o fortalecimento de um grupo de professores de escolas da rede pública (estadual e municipais) do Rio de Janeiro. Investigamos suas práticas e ao mesmo tempo realizamos debates, leituras, discussões, construção e proposição de temas, análise de materiais (sobretudo os livros didáticos que eles utilizam, mas também filmes e outros materiais complementares ou alternativos). Estes professores, de diferentes escolas (todas da rede pública), foram entrevistados e participam de reuniões mensais de preparação, acompanhamento e avaliação, onde são discutidos e compartilhados materiais didáticos, textos e outros instrumentos indispensáveis para o exercício da Lei 10.639, além de palestras sobre temas considerados relevantes pelo grupo. Desta forma, estamos já intervindo diretamente nas práticas deste grupo de professores.

O entrelaçamento consciente de coleta de informações com a influência sobre as práticas dos professores transforma este processo numa pesquisa-ação, tomada aqui como uma perspectiva de investigação militante, que tem 0 
sentido político assumido como motor do trabalho, o que valoriza o rigor nas ações. Vejamos como se desenvolve esta perspectiva.

\section{Leituras e interpretações da Lei}

O texto da Lei 10.639, em seus pontos principais, diz o seguinte:

Art. 1으 A Lei no 9.394, de 20 de dezembro de 1996, passa a vigorar acrescida dos seguintes arts. 26-A, 79-A e 79-B:

"Art. 26-A. Nos estabelecimentos de ensino fundamental e médio, oficiais e particulares, torna-se obrigatório o ensino sobre História e Cultura Afro-Brasileira.

$\S 1^{\text {ㅇ }}$ O conteúdo programático a que se refere o caput deste artigo incluirá o estudo da História da África e dos Africanos, a luta dos negros no Brasil, a cultura negra brasileira e o negro na formação da sociedade nacional, resgatando a contribuição do povo negro nas áreas social, econômica e política pertinentes à História do Brasil.

$\S 2^{\circ}$ Os conteúdos referentes à História e Cultura AfroBrasileira serão ministrados no âmbito de todo o currículo escolar, em especial nas áreas de Educação Artística e de Literatura e História Brasileiras.

"Art. 79-B. O calendário escolar incluirá o dia 20 de novembro como 'Dia Nacional da Consciência Negra'."

Tal texto é resultado de um complexo processo de construção. Sendo conquista de lutas de movimentos sociais há décadas ${ }^{1}$, que são traduzidas e debatidas pelo Congresso Nacional e pelo Poder Executivo Federal (antes, elas já haviam sido "traduzidas" em legislações municipais e estaduais de teor semelhante), este texto é, na verdade, síntese e simplificação da ampla pauta das lutas daqueles que conquistaram a Lei. Com efeito, ao longo de décadas as lutas educativas do Movimento Negro tiveram pautas muito mais abrangentes, mas a relação com o Estado e o processo legislativo resultaram neste texto.

De outro lado, a aplicação deste dispositivo jurídico, como qualquer outro, passa pela sua interpretação - visto que não há lei cuja aplicação seja automaticamente definida. Toda aplicação de lei é resultante de disputas entre interpretações. Isto permite, a um só tempo, que na aplicação da Lei 10.639 possam ser retomados aspectos inerentes à ampla agenda educativa do Movimento Negro ou, por outro lado, que haja uma simplificação da mesma, reproduzindo processos educativos que não cumprem a função de combater valores que sustentam o racismo. Os principais aplicadores da 10.639 são os membros da comunidade escolar (bem como os agentes da produção de políticas educacionais), que se tornam então interlocutores do Movimento 
Negro Brasileiro a partir do momento em que este se coloca como um ator social que disputa e intervém na construção da Educação.

As disputas por interpretações se tornam, portanto, cruciais para pensar a implementação da Lei 10.639. No cotidiano escolar, são comuns falas sobre ela como sendo "a lei do cumpra-se", como uma determinação unilateral e "de cima para baixo do governo sobre a escola", como uma medida excêntrica e extemporânea em relação ao ambiente escolar. Tais interpretações têm impacto direto sobre as formas de implementação ou, mais diretamente, sobre o quanto de anti-racista terá o currículo efetivamente praticado a partir dela (ou contra ela). Enquanto Lei, ela é uma prescrição curricular, que pode se transformar em prática ou acabar distanciada daquilo que é praticado na escola. A dissociação entre currículo prescritivo e currículo praticado se torna então bastante útil para pensar este processo em que interpretações disputam as ações a partir da lei.

Nos colocamos, assim, numa perspectiva de contribuir para atribuir na aplicação da Lei a complexidade das pautas e agendas das lutas que a engendraram. Tomando seu texto (reproduzido acima) como ponto de partida, temos que ele aponta uma série de aspectos, dos quais podemos exemplificar: no artigo $1^{\circ}$, que ela é uma alteração da Lei de Diretrizes e Bases da Educação Nacional, o que indica sua amplidão sobre toda a educação; no artigo 26-A, sua abrangência sobre os níveis fundamental e médio de ensino; no $\S 1^{1}$, ela indica um amplo conjunto de conteúdos disciplinares (o que contrasta com uma interpretação simplificante que é hegemônica nas escolas, que a indica como "a lei que fala da história da África", ou "da cultura negra"); no $\S 2^{\circ}$, algo que é ambiguamente interpretado, que é a incidência disciplinar sobre "todo o currículo escolar", o que abrange todas as disciplinas, mas ao mesmo tempo o destaque dado a Educação Artística, Literatura e História Brasileira, que comumente leva a professores de outras disciplinas a se sentirem descompromissados com a aplicação da Lei; no artigo 79-B, a valorização das lutas dos negros ao incluir o Dia da Consciência Negra (20 de novembro, data eleita pelo Movimento Negro) no calendário escolar - e, muitas escolas ainda insistem em celebrar o dia 13 de maio, oficialmente definido como dia da Abolição da Escravatura.

Este pequeno conjunto de tensões interpretativas que elencamos no parágrafo anterior nos mostra a complexidade do processo de aplicação da Lei. Ela encontra um ambiente escolar composto majoritariamente por atores que não foram preparados para construir uma educação anti-racista, bem como materiais pedagógicos inadequados e portadores de aspectos que oferecem sustentação à reprodução do racismo. É neste ambiente que alguns professores, pais, coordenadores pedagógicos, direções escolares, bem como ativistas anti-racismo, travarão disputas por interpretações na aplicação da Lei. Mas, não apenas no ambiente escolar: Academia, movimentos sociais e 
Estado, todos envolvidos com produção e difusão de materiais de referência, articulação e capacitação de órgãos e instituições definidoras e executoras de políticas educacionais, produção e difusão de conhecimento, entre outros, são arenas de disputa fora da escola, mas também fundamentais para a implementação da Lei 10.639.

\section{A centralidade do Currículo Praticado}

Nossa pesquisa-ação é, portanto, centrada no currículo praticado nas escolas e, em particular, no ensino de Geografia. A prática é nosso ponto de partida e nosso ponto de chegada, aquilo que queremos compreender, atingir e transformar. Por ela perpassam todas as dimensões de intervenção concernentes à aplicação da Lei 10.639.

Este foco no âmbito do "currículo praticado" é fundamental porque a Lei é um regulador da construção do currículo, ela também é currículo, mas é uma "prescrição" - e, não necessariamente, é aplicada ou, tem sua aplicação mediada por interpretações dos atores envolvidos. Existir a Lei não garante uma educação anti-racista. Isto é uma construção, no campo das "práticas" curriculares concretas.

Nossa preocupação se desloca, portanto, para o que é realizado, como é realizado, quais são as condições, quais os desafios para uma prática educacional e para um ensino de Geografia comprometido com a promoção da igualdade racial. Nas reuniões mensais que realizamos, os professores fazem relatos sobre seus trabalhos em cada mês. Estes relatos, que são gravados, transcritos, sistematizados e analisados, nos indicam que, além da dificuldade de formação sobre o tema, da falta de materiais que auxiliem, e do engessamento do programa curricular da disciplina, há outras condições e aspectos que lhes impõem desafios.

O que nosso processo de acompanhamento vem nos indicando - e isto nos orienta na definição e redefinição analítica dos focos de investigação - é que a sala de aula não pode ser lida como terreno da "liberdade criativa" do professor de maneira absoluta. Percebemos, diante da apresentação de dificuldades recorrentes, a existência de restrições à liberdade. Começamos a operar com a idéia de "fatores reguladores" da prática dos professores, para capturar um conjunto de elementos com os quais os professores se confrontam, na sua tentativa de aplicação daquilo que discutimos e propomos em nossas reuniões, para o tratamento da Lei 10.639 em seu ensino de Geografia. Identificamos que as possibilidades dos professores de executar o que é proposto (muitas vezes, por eles próprios nas reuniões) esbarrava nos seguintes "fatores reguladores": 
- o livro didático, que o professor precisa seguir ou, ao menos, dialogar. O livro aparece, na maioria dos contextos educativos, como portador de verdades. Não cumprir o livro ou criticá-lo, ir de encontro a ele, significa romper com um ordenamento de poder, algo que não é simples. Consideramos o livro didático o principal regulador das práticas curriculares na escola e, para construir uma educação anti-racista, precisa-se adotar posturas críticas em relação a ele;

- as relações com outros professores de Geografia - os programas praticados são negociados junto a outros professores da escola, de maneira a não prejudicar alunos que, numa passagem de ano, troquem de professor. Esta negociação é também regulação, pois, se outros professores têm interpretações distintas sobre o racismo e educação, torna-se mais difícil inserir as propostas sugeridas pela pesquisa-ação ao programa de um professor. Também se observa situações em que professores do nosso grupo implementam determinados conteúdos, e estes se chocam com o de outros professores, o que modifica relações (pessoais, afetivas, mas sobretudo, de poder) entre eles;

- relações com professores de outras disciplinas, com quem realizam diálogos, trocas e atividades interdisciplinares. Além disso, mesmo que não haja diálogo entre professores, conteúdos das disciplinas dialogam e, quando um começa a trabalhar as demandas da Lei 10.639, muito facilmente entra em colisão com leituras eurocêntricas de outros professores. Esta colisão disciplinar muito facilmente transborda para relações pessoais e políticas, pois questionamentos dos alunos neste sentido são trazidos para as relações entre os professores;;

- as relações com coordenação pedagógica e demais atores da gestão escolar, sobretudo nos chamados "projetos" temáticos interdisciplinares e de organização de eventos - que, muitas vezes, consomem tempo da própria aula, interferindo na execução do programa planejado e desejado pelo professor.

É evidente que uma série de outros fatores regulam a prática do professor, e aparecem nos relatos que já coletamos e analisamos. Questões como a violência na sociabilidade dos alunos, influência de estruturas criminosas e de narcotráfico, condições de recursos materiais e humanos da escola (ausência ou insuficiência de inspetores potencializando problemas disciplinares e organização de horários), perfil da turma, entre muitas outras, interferem no trabalho realizado - e, na implementação da Lei 10.639. Entretanto, estes fatores reguladores que destacamos nos parágrafos anteriores têm relação com visões de mundo, de educação e de racismo de membros da comunidade escolar que interagem com os professores na implementação da Lei na escola. $\mathrm{E}$, evidentemente, estas visões de mundo têm no ensino de Geografia um importante elemento formador, que discutiremos a seguir.

Geografia, visões de mundo e a Lei $10.639^{\mathrm{ii}}$ 
Acreditamos que, de diversas maneiras, a Geografia tem relação direta com a constituição das relações raciais. Aqui, estamos falando de "raça" não como um conceito biológico (aliás, já superado na própria Biologiaiii), mas, enquanto conceito social, enquanto constructo socialiv que é princípio ordenador de relações sociais - este, se num contexto histórico valeu-se do conceito biológico para se afirmar, hoje já é independente dele, de modo que a desqualificação no campo da Biologia não elimina a raça enquanto dado regulador de comportamentos e relações sociais.

Esta "raça", constructo social, princípio de classificação que ordena e regula comportamentos e relações sociais, tem vinculação direta com a Geografia. Afinal, como bem nos aponta Quijano (2007), quando falamos em "negros", remetemos diretamente à idéia de uma comunalidade, se não biológica, de origem histórico-geográfica: África. Quando falamos em "brancos", o mesmo se repete, com a idéia de uma origem que remete a Europa. O mesmo para "índios", associados à América; "amarelos", associados à Ásia. Estes referenciais são absolutamente fruto de distorções, são construções artificiais que servem para produzir visões de mundo, visões do outro, orientar e regular comportamentos e relações - e, aqui, estamos mais especificamente falando do padrão de relações raciais brasileiro.

Relacionamos "negro" a África mesmo sabendo que, há muito tempo boa parte da África é habitada (também) por grupos que, no padrão de relações raciais brasileiro, não são classificados como "negros" - a chamada "África branca", que muitos autores também questionam. Sabemos também que indivíduos e grupos que no nosso padrão de relações raciais seriam classificados como "negros" estão presentes em populações antigas de outras partes do mundo como alguns grupos aborígenes na Austrália e algumas castas na Índia. Mas, aqui, "negro" tem a ver com África, confundimos a origem dos fluxos de escravizados trazidos para cá como a única região do mundo onde habitavam homens e mulheres de pele escura antes do tráfico atlântico.

Relacionamos "branco" a Europa, mesmo sabendo que não é apenas lá que habitavam historicamente homens e mulheres com estas características, e também que parte significativa dos indivíduos que no padrão de relações raciais brasileiro são classificados como "brancos" não são oriundos do que chamamos de Europa. Aliás, do ponto de vista geofísico, Europa é muito mais uma península da EurÁsia do que um continente em si. O processo de individuação espacial que transforma Europa num continente é, em si, uma distorção sob este ponto de vista, e tem como contraface indissociável a reprodução da percepção de que a África é apenas um país: é a geopolítica das identidades que produz tais percepções. 
Ásia também não é um continente onde há apenas aqueles que no nosso padrão são chamados de "amarelos", mas sim, uma diversidade de grupos que classificamos, dividimos e agrupamos "racialmente". Ou seja, há um conjunto de associações artificiais que sustentam - tentando, de certa forma, "naturalizar" - o constructo de "raça".

Estas associações são, eminentemente, geográficas. Raça passa a ser, por esta ótica, um conceito geográfico, uma noção que se assenta sobre leituras espaciais. A Geografia está, portanto, de uma forma muito subliminar, na base da construção da idéia, das relações e dos comportamentos baseados no princípio de classificação racial. A visão de mundo que a Geografia constrói alicerça as identidades raciais. $O$ ensino de Geografia é um dos principais veículos ${ }^{\mathrm{v}}$ :

(i) Da associação entre grupos raciais e regiões (geoculturais) de origem, que dá esteio à permanência da idéia de raça $\mathrm{a}^{\mathrm{vi}}$ enquanto reguladora de comportamentos, valores e relações sociais, econômicas e de poder;

(ii) $\mathrm{Da}$ divisão dicotômica do mundo (desde Ratzel) entre países desenvolvidos e subdesenvolvidos - e, no meio deles, os países "em desenvolvimento", o que (a) reforça a idéia de uma evolução linear cujo futuro único do mundo é seguir o caminho dos chamados "desenvolvidos", e (b) confere poder nas relações sociais aos indivíduos e grupos cuja historicidade, geograficidade e "corporeidade"vii são remetidos à herança e ligação com estes países e povos ditos "desenvolvidos" e, portanto, superiores;

(iii) Da difusão da monocultura do tempo(espaço) linear, pela forma como se trabalha o papel da técnica como dimensão evolutiva - p. ex., na maneira como é trabalhado o conceito de paisagem, através da divisão entre "paisagens naturais" e "paisagens humanizadas", estas últimas sendo sempre (evolutivamente) a expressão dos avanços tecnológicos sobre a materialidade terrestre. Assim, paisagens que são fruto de experiências simultâneas aparecem como sendo paisagens do passado, paisagens do presente $\mathrm{e}$ paisagens do futuro;

(iv) Da visão do mundo contemporâneo como sendo o transbordamento de processos econômicos, políticos, sociais, militares e culturais da Europa - 0 que aparece com toda força na forma como se ensina sobre os outros continentes, cujos referenciais históricos e espaciais de periodização e regionalização aparecem sempre como resultantes diretos dos processos e interesses eurocentrados, portanto, como se não houvesse protagonismo neles; 
(v) Da difusão de uma visão tecnicista e cartesiana de mundo, p. ex., pela forma como ensinamos Cartografia. De uma forma de representação espacial, ela é transformada em única forma de expressão espacial do mundo, critério de verdade e de existências naturais e sociais, decorrente das possibilidades da racionalidade técnica subjacente ao processo de elaboração dos mapas - que são, melhor dizendo, limitados por esta racionalidade às formas científicoocidentais de ver o mundo, de expressar referenciais de espaço, de tempo e das existências sociais. Esta forma como se trabalha e ensina a Cartografia Escolar dá aos mapas oficiais um caráter de expressão da verdade que é poderoso instrumento de poder através da produção de não existências de grupos sociais, conflitos, saberes, experiências e formas de relação com o mundo.

Todas estas dimensões do Ensino de Geografia contribuem para a construção de referenciais de leitura do mundo que conferem poder a indivíduos e grupos nas múltiplas interações e relações. Têm papel crucial nas relações raciais, no racismo e nas desigualdades raciais que se constroem e aparecem no plano das interações cotidianas entre indivíduos e grupos (ver Sansone, 1996), na construção da lógica e comportamento de instituições (ver Bento, 2002), na definição do acesso aos bens materiais e simbólicos da sociedade (ver Hintzen, 2007, e Paixão, 2003). Sustentam, também, a naturalização das práticas que configuram o racismo e as suas conseqüências sociais sobretudo, as chamadas desigualdades raciais -, com os quais aprendemos e acostumamos a viver e conviver.

No caso brasileiro, esta construção de leituras que naturalizam as práticas cotidianas do racismo em nossas leituras do social está inclusive, na base de um dos pilares ideológicos da idéia de nação, através do chamado "mito da democracia racial" (Guimarães, 1999). Leituras criticando as porosidades desta pretensa democracia racial - indicando, por exemplo, a existência de desigualdades raciais -, já começam a aparecer em livros didáticos, mas ainda é comum os capítulos (ou melhor, quase sempre, o sub-capítulo) que abordam a formação do povo brasileiro atentarem para a diversidade de origens dos brancos e não mostrar a diversidade de origens dos negros e dos índios. Tais assertivas nos levam a indagar em que medida as imagens dos grupos raciais transmitidas pelo ensino de Geografia são democráticas, o que só é possível identificar (e combater) através de uma agenda investigação e ação.

\section{Construindo uma agenda de pesquisa a partir da Lei}


Em nosso processo de investigação dialogamos, portanto, com visões sobre Geografia (e sua dimensão escolar), com disputas de interpretação sobre os desdobramentos da Lei no ambiente escolar e, indiretamente, com as esferas sociais que se relacionam com a escola (via políticas educativas, formação de professores, pressão social, etc). Entretanto, consideramos as lutas do Movimento Negro como o lócus privilegiado de construção dos sentidos da aplicação da Lei 10.639.

Podemos sintetizar o objetivo da Lei como sendo construir uma educação voltada para a igualdade racial, o que implica reposicionar o negro e as relações raciais no mundo da Educação - romper com silenciamentos sobre o racismo no cotidiano escolar, em conteúdos, em materiais e métodos pedagógicos, e na formação de professores. Sendo a Lei uma prescrição, deve-se atentar para o currículo praticado e o currículo oculto, o que comporta aspectos não elencados em grades curriculares mas que compõem o conjunto de aprendizados transmitidos em interações cotidianas ao longo da trajetória escolar de educandos, sejam eles negros ou não.

Com base nisto, propomos então uma estrutura lógica para a pesquisa, compondo-a a partir de cinco vertentes, que são: (i) Inserção e Revisão de conteúdos programáticos do currículo Praticado de Geografia; (ii) Revisão de Práticas, Materiais e Métodos Pedagógicos; (iii) Gestão das Relações Raciais no Cotidiano Escolar; (iv) Relações de Poder na Construção do Currículo Praticado na Escola; (v) Movimento negro, lutas na Educação e escalas da política.

Cada uma destas vertentes é, em nossa leitura, um âmbito de construção da Lei. As vertentes i, ii e iii concernem à sua aplicação, seja na transformação de conteúdos, materiais e ruptura com os mecanismos de silenciamento sobre 0 racismo nas relações no cotidiano escolar. As vertentes iv e $v$ investigam o processo instituinte de formulação e aplicação da Lei, seja nos conflitos, acordos e negociações no âmbito das relações de poder no cotidiano da escola ou nas relações travadas pelo Movimento Negro com os atores do campo educacional (antes e depois da promulgação da Lei). Estas vertentes vêm sendo desdobradas em estudos específicos viii, que utilizam e desenvolvem abordagens metodológicas de investigação (e/ou ação) da pesquisa. Vejamos um pouco mais sobre cada uma das vertentes.

Vertente 1. Inserção e revisão de conteúdos programáticos do currículo praticado de Geografia 
Há uma interpretação corrente da Lei 10.639 de que o seu cumprimento se encerra na inserção de conteúdos sobre África, africanidades, etc., conteúdos que, por deficiência programática ou pela falta de tempo, estavam ausentes do currículo praticado. Inserir conteúdos seria, portanto, buscar completar lacunas de informações não trabalhadas. Apontamos aqui que esta interpretação é incompleta diante dos desafios que a Lei coloca. Os conteúdos apontados pela Lei têm como objetivo intervir na formação das visões de mundo constituídas no ensino escolar, mas eles não cumprem esta função se não estiverem articulados a uma releitura do todo dos conteúdos escolares. Neste sentido, falar de África é fundamental, mas não é suficiente se não fizermos uma desconstrução das narrativas que estruturam as leituras de totalidade-mundo, 0 que implica revisões conceituais, revisões de estruturas, enfim: inserção de conteúdos mas também a revisão de conteúdos. Esta linha tem como eixo central a identificação de um temário, um conjunto de assuntos que são ou não trabalhados nas aulas de Geografia, temas a serem inseridos e temas a serem revistos. Este temário é construído junto com os professores, partindo de suas experiências e informando-as, de maneira a dialogar diretamente com 0 currículo praticado nas aulas de Geografia - e, evidentemente, com os programas dos currícula oficiais dos PCNs. Num primeiro exercício, a título de exemplo e sem pretensão de esgotamento, elencamos aqui 6 conjuntos temáticos:

(a) O debate raça \& modernidade, que aponta como a raça é um princípio regulador de relações sociais fundamental para a afirmação do capitalismo a partir do século XIX, permitindo a estruturação de sistemas de dominação em escala internacional e intercontinental (o eurocentramento do mundo), e intranacional e no cotidiano das relações sociais e sócio-espaciais - a dominação dos brancos, ou, eurodescendentes, que se reproduz ao redor de todo o mundo (Quijano, 2007; Hintzen, 2007) e a hierarquização racial da força de trabalho permitindo ao capital aumentar as taxas de exploração de grupos raciais discriminados e também dos aparentemente favorecidos. Seguimos aqui a idéia de uma leitura de totalidade de um sistema-mundo-modernocolonial, defendida (ou, construída) por Wallerstein (1991), Quijano (2000, 2005, 2007), Mingolo (2003, 2004) e Porto-Gonçalves (2005, 2007), entre outros.

(b) O ensino sobre África, marcado hoje pela influência das narrativas eurocentradas. Os marcos estruturantes do que se fala sobre África (referenciais espaciais e temporais, regionalização e periodização) são todos remetidos ao contato com a Europa - o mesmo se aplica às Américas e Ásia, quando a recíproca não é verdadeira: a colonização só é definidora do que são os continentes periféricos, mas o papel dela para as revoluções industriais, 
econômicas, sociais e políticas na Europa não é abordada. Desconstruir e reconstruir a idéia de totalidade-mundo e fazer o mesmo para África é, portanto, um exercício fundamental. África é retratada no ensino sempre através de seus aspectos pejorativos, tragédias sociais, associação a estereótipos degradantes (primitivismo, p.ex.), enfim, uma abordagem que referencia num quadro social adverso de África o quadro de inserção social subalternizado e inferiorizado dos descendentes de africanos na experiência da diáspora.

(c) As Comunidades Remanescentes de Quilombos - que são, hoje, milhares catalogadas em quase todos os estados do país. Elas são marcas espaciais (rugosidades, no dizer de Milton Santos) das resistências dos negros à escravidão, portanto, uma geo-grafia de lutas históricas. São a marca também de que a luta pela terra hoje tem um componente racial radical (Fernandes et al, 2007).

(d) A Segregação Sócio-Espacial nos meios urbanos, que vem sendo também lida através de seu viés racial por diversos autores (Campos, 2005; Rios Neto e Riani, 2007; Rolnik, 2007). Desde a construção de imaginários sociais que associam negritude a espaços pobres (com uma linha de continuidade histórico-espacial entre quilombo e favela, que nos mostram Campos e Rolnik) à concretude da desigualdade racial espacializada do acesso a bens de consumo coletivo (Rios Neto e Riani, 2007), esta problemática deve ser abordada no ensino de Geografia.

(e) Espacialização de dados sobre desigualdades raciais, em diferentes escalas, além do urbano - há trabalhos, sobretudo os de Marcelo Paixão (destacamos aqui aquele sobre as desigualdades raciais no índice de Desenvolvimento Humano no Brasil - ver Paixão, 2003), fazendo análises em escala estadual, intra e inter-regional e nacional, com rico material cartográfico, e que pode ser utilizado nas aulas de Geografia da População.

(f) As "Experiências de Espaço" de diferentes indivíduos e grupos, debate que diz respeito a como a vivência do cotidiano de cada um é influenciada por uma organização espacial das relações raciais: há contextos (temporal e espacialmente organizados) em que o dado racial é um elemento mobilizado como regulador das relações sociais e "contextos de interação" (Goffman, 1975) onde esse dado não é relevante - ambos podem se dar no mesmo "cenário" em momentos distintos, ou em distintos cenários ao mesmo tempo. Sansone (1996) nos fala de "áreas moles" e "áreas duras" das relações raciais, contextos organizados no espaço e no tempo em que a raça é ou não importante nas relações sociais. Isso impacta as experiências de espaço, o ire-vir, na medida em que indivíduos e grupos subalternizados causarão, em 
determinados contextos, sentimentos de espanto, estranhamento e até mesmo repulsa - contextos e lugares onde sua presença é indesejada. Depoimento colhido em entrevista que já realizamos com uma das professoras que integram nosso grupo apontou trabalhar isto com os alunos no momento em que ela discute o conceito de "fronteira": ela fala de "fronteiras visíveis" e "fronteiras invisíveis", sendo estas últimas exatamente aquelas que se impõem através constrangimentos a indivíduos e grupos indesejados em lugares e contextos determinados. É mais um desafio para a aula de Geografia.

Estes são apenas alguns ensaios que já iniciamos na construção deste temário onde deve incidir a inserção e revisão de conteúdos para atender à Lei 10.639. Muitos outros vêm sendo acrescentados e desenvolvidos no desenrolar do projeto.

\section{Vertente 2. Revisão de Práticas, Materiais e Métodos Pedagógicos}

Este componente parte da idéia de que há insuficiências nos materiais pedagógicos para o tratamento das demandas colocadas pela Lei 10.639. Com efeito, o principal instrumento pedagógico utilizado no ensino básico é o livro didático, cujo tratamento das questões relativas ao escopo da Lei merece uma profunda revisão.

Como o temário apontado acima mostra, para aplicar a Lei é necessário tensionar o cotidiano, as vivências e experiências dos indivíduos, o que em si coloca um desafio para a própria proposta pedagógica: ela tem que estar em alguma forma de sintonia com estas vivências, e não se deter apenas a conhecimentos abstratos e raramente vinculados ao cotidiano do aluno. $O$ resultado dessa dissociação entre propostas pedagógicas (aludimos aqui a conteúdos, métodos e aos materiais correspondentes) e o cotidiano do aluno é que, correntemente, quando o assunto em tela é a temática das relações raciais, o aluno não encara como um saber escolar (e/ou científico), ou seja, para ele isso "não é aula".

Colocam-se, portanto, alguns desafios: compreender e fazer uma análise crítica de como os materiais pedagógicos tratam os temas relativos à Lei; transformar a prática pedagógica de maneira que o tratamento da Lei não apareça como algo externo aos conteúdos escolares. Tais desafios vêm sendo enfrentados (i) através de um diálogo intenso com nosso grupo de professores envolvidos no processo de pesquisa e (ii) através de uma análise de livros didáticos de Geografia, no que tange ao tratamento (ou não) do temário relacionado à Lei 10.639. Num primeiro ensaio, metodológico, as três vertentes de análise dos livros didáticos a serem adotadas são: 
(a) Imagem do negro - constitui-se de uma avaliação quantitativa (quantas vezes o negro aparece no livro didático, em comparação a outros grupos raciais?) e qualitativa (como o negro aparece? Quais as suas expressões? Quais as suas inserções social, profissional, etc.? Em que espaços ele aparece?) das imagens do negro. Vale ressaltar que esta análise de imagem independe do temário abordado, por partirmos do pressuposto de que tais imagens fornecem referenciais de construção de subjetividades para os alunos.

(b) Temas - constitui-se de um balanço de quais os temas abordados ou não, diretamente vinculados ao escopo da Lei 10.639. Este balanço contempla que temas são tratados e também como eles são tratados. Conforme nos alerta Ribeiro (2004), disputa-se hoje nas mídias não apenas a veiculação de imagens, mas também as leituras sobre os significados dessas imagens, que podem ser estereotipados, simplificados e distorcidos, o que a autora chama de "deslizamentos de significado". A título de incipiente exercício analítico, poderíamos exemplificar com a forma como são apresentados (quando o são) os quilombos: lugares para onde fugiam os escravos - quase que incidentais -, e não como marcas de um projeto de resistência e luta articulada em prol de um modelo de sociedade mais igualitário que era confrontado como alternativa à ordem escravocrata (Moura, 1988), e nem como um vetor de ressignificação da luta pela terra na contemporaneidade (que não é apenas luta pela propriedade mas sim pelos territórios, como continente de práticas, saberes, culturas e relações sociais conforme nos aponta Arruti, 1999 e 2002).

(c) Estrutura - Quais são os princípios de visão e di-visão dos conteúdos? A estrutura revela não apenas matrizes teóricas, mas também, as formas de construção de visão de mundo. Ela reflete formas de construção de identidades territoriais, ao construir discursos classificatórios sobre espaços associados a grupos sociais (Tonini, 2002).

Estas são as questões que norteiam esta dimensão de análise dos livros didáticos.

\section{Vertente 3 - Gestão das Relações Raciais no Cotidiano Escolar}

O objetivo da Lei 10.639, segundo nossa interpretação, é reposicionar o negro $e$ as relações raciais no mundo da educação. Este reposicionamento necessariamente articula temas, materiais, práticas pedagógicas, mas, também, a forma como a escola encara as relações raciais no seu cotidiano e a forma como isto se relaciona com os conteúdos trabalhados. Com efeito, o racismo no cotidiano escolar que vem sendo apontado por diversos autores, em práticas de professores, da direção, nas relações entre os alunos mas, também, pela veiculação de conteúdos que autorizam e legitimam a 
hierarquização e a subalternização de indivíduos e grupos. Acredita-se que com o atendimento às demandas de conteúdos apontados pela Lei 10.639, estas relações serão positivamente impactadas, num educar para a igualdade racial. Este componente atenta exatamente para estas respostas comportamentais - posturas, reações, dizeres e não dizeres de alunos, professores, coordenadores. Tomamos como base os depoimentos dos professores nas reuniões mensais.

\section{Vertente 4- Relações de poder na construção do currículo praticado na escola}

A implementação da Lei 10.639 se dá tanto no âmbito do trabalho de cada disciplina quanto na dimensão coletiva (trans, multi e interdisciplinar) do currículo escolar. Isto coloca uma questão, que brota em nosso diálogo com os professores: se o cotidiano laboral das escolas onde nossos professores atuam (todas pertencentes à rede pública) é marcado por uma autonomia do professor no trabalho com suas turmas, há também importantes dimensões de negociação e de construção coletiva, tanto (a) intra disciplinar (coletivos escolares e de rede voltados, no nosso caso, para o ensino de Geografia) quanto (b) extrapolando os trabalhos das disciplinas (coordenação pedagógica, trabalhos multi e interdisciplinares, projetos pedagógicos, atividades de projetos, diálogos entre conteúdos transversalizados em diferentes disciplinas que se complementam ou se chocam, etc.).

Isto coloca o tratamento da Lei 10.639 como objeto, como agenda de negociação no cotidiano escolar. Tais negociações envolvem múltiplos atores: professores, direção, coordenação pedagógica, funcionários de apoio, outras esferas de coordenação institucional em nível de rede, etc. Nossas observações nos mostram o quanto é crucial para a implementação da Lei compreender como ela sofre influência de relações de poder que interferem sobre a construção do currículo que é praticado efetivamente. Arenas oficiais (Conselhos de Classe, reuniões pedagógicas, Fóruns disciplinares, etc.) e arenas ocultas (intervalos na sala dos professores, encontros informais no corredor, no refeitório e em outros espaços); agendas oficiais (Projeto Político Pedagógico, Atividades de Projetos, temas transversais a serem trabalhados pela escola) e agendas ocultas (disputas por poder dentro da escola ou dentro da rede, constituição de grupos por afinidade pessoal, ideológica ou outra, etc.); todas essas dimensões influenciam a implementação da Lei, e seu caráter decisivo as tornaram objeto de investigação no âmbito da pesquisa.

Nosso grupo de professores nos oferece riquíssimas possibilidades neste sentido - cada um tem uma inserção diferente, não só em termos de rede (municipal e/ou estadual), mas também são diversas as relações que cada um 
tem com os contextos. Trata-se, na verdade, de contextos escolares diferentes: um trabalha como coordenador pedagógico numa escola mas está como professor em outra escola; cada professor está numa escola com um grupo diferente, e com acolhidas diferentes; uma das professoras que atua numa rede municipal pequena foi designada responsável por construir uma proposta para a rede; enfim, uma série de situações se nos apresentam.

\section{Vertente 5: Movimento negro, lutas na Educação e escalas da política}

A Lei 10.639 é dialeticamente uma conquista e um instrumento do Movimento Negro em sua luta, que então coloca a educação como um campo prioritário para a superação do racismo e se apresenta como um ator social que disputa este campo. Buscamos, então, compreender as formas como o movimento influencia a construção desta agenda educativa e como ele atua política e educativamente disputando o campo.

Marcado por uma pluralidade organizativa, este movimento é um "campo", onde atores de distintas formações e perfis institucionais são movidos conflitivamente pela luta contra 0 racismo, o que permite então que haja entidades e/ou militantes do Movimento Negro dialogando/disputando a interpretação e aplicação da Lei 10.639 em escolas, coordenadorias, secretarias (municipais e estaduais) e ministério da Educação, universidades (para a produção de conhecimento e formação de professores), enfim, nas diversas "arenas" em diversas "escalas", onde se disputam ações que podem contribuir ou dificultar a aplicação da Lei. A idéia de uma "governança difusa" do Movimento Negro no campo das políticas educativas, que temos proposto, se apresenta como bastante promissora na compreensão desta forma de atuação e de mobilização de recursos no campo da Educação.

\section{Considerações Finais}

Ao olharmos os pilares de um programa de investigação sobre a Lei 10.639 e o ensino de Geografia, centrado na dimensão da prática (mas que só é possível através do rigor teórico e metodológico na pesquisa-ação), nos vemos na verdade diante de um conjunto de desafios - a um só tempo acadêmicos, escolares, teóricos e políticos.

A produção de um currículo (não só de Geografia, mas escolar) que contemple as diferenças dos alunos sem refleti-las de maneira hierárquica, sob uma roupagem pretensamente universalista, é o primeiro desafio. Com efeito, matrizes universalistas não raro oferecem em realidade referenciais identitários de posicionalidade hierarquizantes, ao silenciar-se sob o manto da neutralidade 
em relação a princípios de dominação e exploração que estruturam violências no cotidiano das relações capitalistas. Como pode ser um currículo (e, em particular, um ensino de Geografia) que projete uma igualdade real entre diferentes?

Com certeza, o caminho é longo. O que buscamos aqui foi compartilhar alguns passos na tentativa de aplicação da 10.639. Os estudos que temos feito, conforme se pode ver nos outros textos deste volume, ajudam a dar a medida dos desafios enfrentados.

\section{Notas}

I - Santos (2005) nos mostra reivindicações de escopo semelhante ao da 10.639 no estatuto da Frente Negra Brasileira na década de 1930, nas pautas do Teatro Experimental do Negro no final da década de 1940, entre tantas outras iniciativas da luta anti-racismo - o que mostra o longo percurso histórico e social de construção desta agenda educativa.

II - Uma das professoras que acompanhamos, numa escola da rede municipal do Rio de Janeiro, começou a ser estigmatizada por colegas professores, como "radical" e "racista às avessas". Estes estigmas são parte das práticas (táticas e estratégias) de silenciamento da denúncia do racismo, padrão que é repetitivo e fundamental para a manutenção de uma ordem de dominação racial que, ao mesmo tempo, é chamada de "democracia racial". Ver, sobre estas práticas cotidianas sofisticadas e aparentemente democráticas de manutenção do racismo, o texto de Camino et al. (2001).

III - Retomamos aqui apontamentos feitos em Santos (2009).

IV - A este respeito, ver Pena (2005).

V - Quijano nos auxilia a compreender a fragilidade da noção biológica da "raça", ao compará-la à construção da idéia de "gênero", que segundo ele "(...) é um constructo mental fundado nas diferenças sexuais, que expressa as relações patriarcais de dominação e que serve para legitimá-las. $E$ alguns propõem agora que, analogamente, há que se pensar também a 'raça' como outro constructo mental, esse fundado nas diferenças de "cor". Assim, "sexo" está para "gênero" assim como "cor" estaria para a "raça". Entre ambas as equações existe, sem embargo, uma inescapável diferença: a primeira delas tem lugar na realidade; a segunda, em absoluto." (pg. 46) e continua: "Isto não ocorre, de modo algum, nas relações entre "cor" e "raça". Antes de tudo, é fundamental abrir de par em par a questão do termo "cor" enquanto algo que se refere às características das pessoas. A própria idéia de "cor" nesta relação é um constructo mental. Se é dito que há "cores" políticas ("vermelhos", "negros", 
"brancos"), todo mundo está, presumivelmente, disposto a pensá-lo como uma metáfora. Mas, curiosamente, não ocorre assim quando se diz que alguém é da "raça branca", ou "negra", "índia", "pele vermelha" ou "amarela"! Mais curiosamente ainda, poucos pensam espontaneamente que se requer uma total deformação do olhar para admitir que "branco" (ou "amarelo" ou "vermelho") possa ser a cor de uma pele em algum sentido." (pg. 47)

VI - Falamos aqui de tendências hegemônicas no Ensino de Geografia. Há, evidentemente, textos, professores, escolas e experiências críticas que tentam romper com estes traços que estamos apontando aqui - algumas das quais temos acompanhado em nosso grupo de pesquisa. Entretanto, registre-se que os próprios professores e coordenadores pedagógicos que acompanhamos revelam suas dificuldades de romper com estes cânones.

VII - Aqui falamos em sentido amplo, de permanência da idéia de raça no senso comum, no imaginário social, e mesmo nas "sociologias espontâneas" e no "senso comum científico", de que falam Bourdieu, Chamboredon e Passeron (1999), englobando assim também visões de mundo que exercem influências sobre as próprias investigações científicas sobre o mundo e sobre as relações raciais - aquilo que os autores denominam "prenoções": “(...) opiniões primeiras sobre os fatos sociais [que] apresentam-se como uma coletânea falsamente sistematizada de julgamentos com uso alternativo. (...) 'representações esquemáticas e sumárias' que são 'formadas pela prática e para ela', retiram sua evidência e 'autoridade', como observa Durkheim, das funções sociais que desempenham."(pp. 23-4). Estas, povoam os discursos de agentes distintos, que ocupam posições diversas em relação à problemática em questão, e se apresentam com diferentes acúmulos de reflexão.

VIII - É importante a menção à corpo-política e à ego-política do conhecimento, de que falam Frantz Fanon e Gloria Anzaldua (apud Grosfoguel, 2005, 2006).

IX - Os textos que compõem este volume são exemplos destes estudos, desenvolvidos por estudantes e pesquisadores vinculados ao grupo, seja na graduação ou na pós-graduação.

\section{Referências Bibliográficas}

- Arruti, José Maurício. “Propriedade ou território?”. In: Tempo e Presença, v. 21, n. 307, set/out 1999.

"Territórios Negros". In: KOINONIA. Territórios Negros - Egbé: Relatório Territórios Negros. Rio de Janeiro: Koinonia, 2002.

- Bento, Maria Aparecida da Silva. "Branqueamento e branquitude no Brasil". In: Carone, Iray \& Bento, Maria Aparecida da Silva (orgs.). Psicologia 
social do racismo: estudos sobre branquitude e branqueamento no Brasil. Petrópolis: Vozes, 2002.

- Bourdieu, Pierre; Chamboredon, Jean-Claude; Passeron, Jean-Claude. A profissão de sociólogo: preliminares epistemológicas. Petrópolis: Vozes, 1999.

- Camino Leôncio; Silva, Patrícia da; Machado, Aline; Pereira, Cícero. "A face oculta do racismo: uma análise psicossociológica". In: Revista Psicologia Política/Sociedade brasileira de Psicologia política. V. 1, no 1 (jan/jun. 2001), São Paulo.

- Campos, Andrelino. Do Quilombo à Favela: A produção do "espaço criminalizado" no Rio de Janeiro. Rio de Janeiro: Bertrand Brasil, 2005.

- Fernandes, Bernardo Mançano et. Al. "A terra e os desterrados: o negro em movimento - um estudo das ocupações, acampamentos e assentamentos do Movimento dos Trabalhadores Rurais Sem Terra". In: Santos, Renato Emerson dos (Org.) "Diversidade, Espaço e Relações Étnico-Raciais: o Negro no Ensino de Geografia". Belo Horizonte: Ed. Autêntica, 2007.

- Goffman, Erving. A representação do eu na vida cotidiana. Petrópolis: Vozes, 1975.

- Grosfoguel, Ramón. Descolonizando los paradigmas de la economíapolítica: transmodernidad, pensamiento fronterizo y colonialidad global. 2005,

Disponível

em:

http://www.grupalfa.com.br/arquivos/Congresso_trabalhosll/ palestras/Ramon.pdf

La descolonización de la Economía Política y los estudios postcoloniales: transmodernidad, pensamiento fronterizo y la colonialidad global. Revista Tabula Rasa, n. 004, Bogotá, 2006, pp. 1746.

- Guimarães, Antônio Sérgio Alfredo. Racismo e Anti-Racismo no Brasil. São Paulo: Fundação de Apoio à Universidade de São Paulo; Ed. 34, 1999.

- Hintzen, Percy. "Diáspora, globalização e políticas de identidade". ?". In: Santos, Renato Emerson dos (Org.) "Diversidade, Espaço e Relações Étnico-Raciais: o Negro no Ensino de Geografia”. Belo Horizonte: Ed. Autêntica, 2007.

- Mignolo, Walter. Histórias locais / projetos globais: Colonialidade, saberes subalternos e pensamento liminar. Belo Horizonte: Editora UFMG, 2003.

. "Os esplendores e as misérias da 'ciência': colonialidade, geopolítica do conhecimento e pluri-versalidade epistémica". In: Santos, Boaventura de Souza (org.). Conhecimento prudente para uma vida decente: um discurso sobre as ciências revisitado. São Paulo: Cortez, 2004.

- Moura, Clóvis. Sociologia do negro brasileiro. São Paulo: Ed. Ática, 1988.

- Paixão, Marcelo. Desenvolvimento Humano e Relações Raciais. Rio de Janeiro: DP\&A, 2003. 
- Pena, Sérgio. Razões para banir o conceito de raça da medicina brasileira. História, Ciências, Saúde - Manguinhos, v. 12, n. 1, p. 321-46, maioago. 2005.

- Porto-Gonçalves $(2005,2007$

- Quijano, Aníbal. "Colonialidad del poder y clasificacion social". In: Journal of World-Systems Research, vi, 2, summer/fall 2000, 342-386 Special Issue: Festchrift for Immanuel Wallerstein - Part I. . "Colonialidade do poder, eurocentrismo e América Latina". In: Lander, Edgardo (Org.) A Colonialidade do saber: Eurocentrismo e Ciências sociais - Perspectivas latino-americanas. Buenos Aires: CLACSO, 2005.

"O que é essa tal de raça?". In: Santos, Renato Emerson dos (Org.) "Diversidade, Espaço e Relações Étnico-Raciais: o Negro no Ensino de Geografia". Belo Horizonte: Ed. Autêntica, 2007.

- Ribeiro, Ana Clara Torres. Por uma Cartografia da Ação: pequeno ensaio de método: Projeto do Observatório LASTRO. 01. ed. Rio de Janeiro: $0,2001 / 2004$, mimeo.

- Rios Neto, Eduardo e Riani, Juliana de Lucena Ruas. "Desigualdades raciais nas condições habitacionais na população urbana". In: Santos, Renato Emerson dos (Org.) "Diversidade, Espaço e Relações ÉtnicoRaciais: o Negro no Ensino de Geografia". Belo Horizonte: Ed. Autêntica, 2007.

- Rolnik, Raquel. "Territórios negros nas cidades brasileiras: etnicidade e cidade em São Paulo e Rio de Janeiro". In: Santos, Renato Emerson dos (Org.) "Diversidade, Espaço e Relações Étnico-Raciais: o Negro no Ensino de Geografia". Belo Horizonte: Ed. Autêntica, 2007.

- Sansone, Lívio. "Nem somente preto ou negro: o sistema de classificação racial no Brasil que muda". In: Afro-Ásia, n. 18, 1996, Salvador, p. 165188.

- Santos, Sales Augusto dos. "A Lei 10.639/2003 como fruto da luta antiracista do Movimento Negro". In: Santos, Sales Augusto dos; Braga, Maria Lucia Santana; Magalhaes, Ana Flavia Pinto; Lisboa, Andreia.. (Org.). Educacao anti-racista: caminhos abertos pela Lei Federal 10.639/2003. 1 ed. Brasília: MEC/SECAD, 2005, v. 3, p. 21-37.

- Santos, Renato Emerson dos. Rediscutindo o Ensino de Geografia: Temas da Lei 10.639. Rio de Janeiro: CEAP, 2009.

- Tonini, Ivaine. Identidades capturadas: Gênero, geração e etnia na hierarquia territorial dos livros didáticos de Geografia. Porto Alegre: Tese de doutoramento apresentada à Faculdade de Educação da Universidade Federal do Rio Grande do Sul, 2002.

- Wallerstein, Immanuel. Unthinking Social Science: the limits of nineteenthcentury paradigms. Cambridge: Polity Press, 1991 
REVISTA TAMOIOS

TAMOIOS. ANO VII. № 1, 2011 - ISSN 1980-4490 